\title{
The research on physical simulation of land subsidence in China
}

\author{
Aihong Zhou ${ }^{1, a^{*}}$,Shaokang $\mathrm{Li}^{1, \mathrm{~b}}$ and Chenhui Wang ${ }^{1, \mathrm{c}}$ \\ Shijiazhuang University of Economics, Shijiazhuang,050031,P.R.China \\ asensiblecall@163.com, ${ }^{\mathrm{b}} 729479957 @ q q . c o m,{ }^{c} 1015292804 @ q q . c o m$
}

\section{Keywords: Land subsidence; Physical simulation; Research status; Development trend}

Abstract. The land subsidence has become a common widespread geological disaster in the world. With the acceleration of urbanization and industrialization, the role of human economic and engineering activities in the land subsidence becomes the decisive key factors. Land subsidence has become increasingly a threat to human life and social development. The present situation of physical simulation of land subsidence at home and abroad is introduced, and the problems and future development trend of physical simulation tests are summarized.

\section{Introduction}

Caused by the natural and human factors, the land subsidence is a geological hazard which is a reduction of regional elevation resulted from the compactness of soil [1]. Since the first large-scale land subsidence happened in Niigata, Japan in 1898, the world has a total of more than 60 countries occurred land subsidence, direct or indirect threat to the survival of mankind and caused hundreds of millions of economic losses. Along with the expansion of the scope of human activities, the land subsidence geological disasters are becoming more and more serious. The world related organizations and institutions pay more attention to this problem, and launched a number of academic conferences to study, solve and predict land subsidence problems. One of the core issues in the academic research is the physical simulation. By taking into account the different factors to carry out physical tests, more true and accurate land subsidence can be displayed and its occurrence conditions, triggering factors and other related academic issues can be revealed. Furthermore, the land subsidence can be predicted.

\section{Current situation of physical simulation of land subsidence}

Because of the growing ground subsidence, the relevant scholars and researchers at home and abroad have done a series of indoor and outdoor experiments to explore the relationship between the ground subsidence and the impact factors, and to predict its harm. The land subsidence is caused by the specific geological environment and is influenced by many kinds of factors. The large-scale continuous development and utilization of groundwater and oil and other resources lead to the rapid development of regional land subsidence and become the main factors of land subsidence. So it is very important to consider the influence of groundwater to carry out simulation test.

In 1950s, Japanese scholars, Yamamura Kitaro, studied the relationship between groundwater and surface water by using large scale physical simulation experiments. One set of experiments was a clay layer covered in a sand aquifer, and the other set of experiments was the soil layer of the four layers of clay and sand. The top surface of the soil layer is filled with a free surface water, which mainly simulate the ground activities due to the reduction and the recovery of the confined water head in the aquifer [2].

In 2010, by carrying out experimental research, Professor $\mathrm{Wu}$ has introduced the mature 
groundwater recharge technology in deep confined aquifer to the shallow aquifer, and analyzed the effect of artificial recharge of shallow groundwater to control the ground subsidence by monitoring the land surface deformation synchronously. According to the experimental results, the practical applicability of the pressure back to the uplift of the groundwater level and control the ground subsidence is very good [3].

In 2010, combined with the actual operating conditions of Nanjing metro, Professor Ma developed a new type of pumping precipitation simulation experiment system to simulate on-site pumping station. The experimental results show that the land subsidence in the early stage of the pumping water increases with the decrease of water level, but due to the water supply at the near edge, the ground is on the rise after the pumping quantity is stable at the later stage [4].

In 2011, on the basis of the existing results, Professor $\mathrm{Xu}$ designed and developed a set of laboratory test device for land settlement to improve the saturation method of samples. The land subsidence caused by the release of water is simulated by using the device. From the response of the land subsidence to the water level changes and the changes of the pore water pressure during the process, the lag of land subsidence is studied [5].

In 2012, Professor Li carried out a group well pumping test at a subway station in Tianjin and analyzed the land settlement. During pumping test, ground elevation is downward trend. With the growth of pumping time and additional load, the land settlement is greater, but is decreased when stop pumping water, which indicates that the surface subsidence will have a certain rebound with the recovery of the water level [6].

In 2012, Professor Wang had a further discovery of the original theory. Combined with the actual project, through the indoor model test, the effect of water level changes on the land subsidence is studied systematically. When the water level is reduced, the soil water pressure is close, the deformation is slow and has a long time. When the water level is reduced, the water in soil is released and compacted. In the early stage of drainage, the deformation is relatively slow and there is a long lag time. When the water level rise, the soil layer rebound, the ground to produce uplift, due to the visco-elastic-plastic deformation characteristics of the soil, even if the water level rise to the initial state, there is still a part of the deformation is still unable to recover, becoming a permanent settlement [7].

Although different pumping test results are slightly different, the results further proved that the influence of ground water on the land settlement is very large. In addition to the groundwater is over extraction caused by water level fall, the occurrence of ground subsidence is related to other factors, and the effect of different factors on the ground subsidence and the law is not the same, many scholars have carried out experiments to explore.

In 2010, with the help of centrifugal model test method, Professor Tang of Tongji University and relevant researchers explored the effect of building volume rate on the engineering land subsidence of the intensive construction group in Shanghai soft soil area. The experimental results show that the soft soil layer is a main component of engineering land subsidence, the subsidence variation with time of strata and regional point accords with exponential function. The superimposition effect of dense buildings on land subsidence is obvious and increases with the floor area ratios. In a certain floor area ratio, the superimposition effect of land subsidence has a significant time effect. The floor area ratio should be controlled in a certain extent to prevent land subsidence exceeding allowable value, which will cause instability of urban environment [8] . 
At the same time, the influence of the environmental effect on the land subsidence in Shanghai area is studied by indoor simulation test. The deformation characteristics of different soil layers, the influence of adjacent buildings, and the variation of stress, including soil pressure and pore water pressure, in the center and surrounding areas are discussed. The results show that the Shanghai soft soil layer is the main part of the land subsidence. The urban land subsidence caused by the environmental effect of high rise building group is characterized by the fact that the land subsidence over the width of a building's foundation is greater than that of the building itself, especially in the central area of adjacent buildings. There is a obvious superposition effect of settlement on the surface deformation of the dense high rise buildings, and the settlement amount exceeds the allowable value, which brings the instability factor.

\section{The existing problems}

With the in-depth study of land subsidence, the importance of physical simulation experiment is significant, but there are many problems to be solved in the process of simulation test [9].

The deformation characteristics of soil layers are very complex, and the deformation characteristics of different soil layers and their variation with space and time in the process of regional land subsidence should be considered. The model of elastic, elastic plastic or elastic plastic viscosity is established according to the deformation characteristics of different soil layers at different stages and different positions, but the same model can not be used for all the soil layers in the whole region.

At present, the domestic physical simulation test conditions are too single, the factors are not comprehensive, and the indoor test can not accurately restore the land subsidence conditions, while natural factors are complex which affects the accuracy of the test results to some extent.

When the physical simulation experiments are carried out, the human interference factors and the problems of equipments' operation are too much, which all will affect the accuracy of the results.

\section{The trend in the future}

From the point in recent years, there has been a great development in the land subsidence both in depth and in breadth. The subject on land subsidence simulation has been developed from the initial indoor model and experiment to the combination of the indoor test and the soil layer model, from the qualitative analysis to quantitative analysis and from the simple model of soil deformation to the coupling model of groundwater and soil.

With the development of science and technology and capital investment, it is confirmed that the physical simulation test of ground settlement will overcome the existing problems and contradictions, and the human factors and natural factors of the inducing factors are more comprehensive, which makes the experimental research more scientific, accurate and comprehensive.

\section{Summary}

At present, although a number of ground subsidence research seminars are held at home and abroad, the problem of land subsidence is mainly studied by numerical simulation analysis. Due to the problems of insufficient funds, natural environmental interference, and other issues, there are still some problems for the physical simulation experiment, especially in outdoor large scale experiments, many problems still need to be improved. All numerical simulation is based on the actual engineering, and can not ignore the practical problems of the project. The establishment of 
physical simulation experiment can make the ground settlement problem more close to reality, so physical simulation should be paid more attention and combined with other research directions to ease land subsidence.

\section{Acknowledgements}

In this paper, the research was sponsored by the National Science Foundation of China (Grant No. 41301015) and the Key Program of the Hebei Education Department (Grant No. ZD2015073).

\section{References}

[1] Zhen-dong cui, Tang Yiqun, Land subsidence status quo and research at home and abroad, Journal of northwest earthquake. 29 (2007) 275-278.

[2] Hai-tao dai, Physical model test on Xi 'an land subsidence study, Ph.D. Chang 'an university, 2009.

[3] Wu jianzhong, Hanmei Wang, Tian-liang Yang, Experimental research on artificial recharge to shallow aquifer to control land subsidence due to construction in Shanghai city, Modern geology. 23 (2010) 1194-1200.

[4] Zhili Ma, guang-feng Chen, Zhao Rong etc., A new indoor simulating system for ground settlement due to pumping, Water resources and hydropower technology. 41(2010) 39-430.

[5] Hai-yang Xu, zhi-fang Zhou, Zongqi Gao, Experimental research of hysteretic effect of land subsidence caused by water releasing, Chinese Journal of Rock Mechanics and engineering. S2 (2011) 3595-3601.

[6] Yiming Li, Wenhui Wei, Li Cai, Group of well pumping test and the analysis of land subsidence and its application of a subway station in tianjin, Railway Engineering. 11 (2012) 93-97

[7] Xinghan Wang, Water level changes on the experimental study of high-rise buildings induced ground subsidence influence, China's western science and technology. 10 (2012) 51-53.

[8] Yiqun Tang, Shou-peng Song, Chen Chou, Study of land subsidence rule dense buildings under different floor area ratio, Chinese Journal of Rock Mechanics and engineering. S1 (2010) 3425-3431.

[9] Shu-jun Ye, Yu-qun Xue, Shanghai regional land subsidence model of soil deformation characteristics research, Journal of geotechnical engineering. 2 (2005)140-147. 